\title{
Online Banking in Italy. "Widiba Bank" Case Study, PESTLE and DEA Analysis
}

http://doi.org/10.21272/fmir.5(1).87-97.2021

Alessio Faccia, ORCID: https://orcid.org/0000-0001-7231-6774

Ph.D., Lecturer, Coventry University, United Kingdom

Luigi Pio Leonardo Cavaliere, ORCID: https://orcid.org/0000-0003-3169-567X

University of Foggia, Foggia, Italy

\begin{abstract}
Given the great interest and impact generated by the previous article on the "Widiba Bank" case study published in this journal, the authors intend now to provide more insights on the analysis of the current Italian framework. A PESTLE analysis is therefore carried out to identify the main financial and environmental alternative strategies. The object of research is the chosen company Widiba Bank because, despite being a latecomer in the Italian online banking industry, its success demonstrated the importance of the adoption of targeted strategies in the digitized world. The performed analysis PESTLE allowed to provide many insights from different perspectives. The paper then confirmed the analyses by comparing the last 5 years' performances (measured by the ROE ratio and Deposits Growth as Inputs, and Assets Growth as an Output) of the Italian Online Banking industry (average of the years 2016-2019). The data are retrieved from the Italian Public Registry of Incorporated Companies (managed by the Italian Chambers of Commerce) and processed using the DEA SOLVER software. This article strategically enhanced the knowledge of a previous one focused on the same bank by providing different perspectives and, therefore, a comprehensive view of the Widiba bank case study. It, therefore, aims at producing useful resources for business schools, practitioners, and experts.
\end{abstract}

Keywords: PESTLE Analysis, Widiba Bank, Online Banking, DEA analysis, Italy, Fintech.

JEL Classification: G21, O35, D79.

Cite as: Alessio Faccia, Luigi Pio Leonardo Cavaliere (2021). Online Banking in Italy. "Widiba Bank" Case Study, PESTLE and DEA Analysis. Financial Markets, Institutions and Risks, 5(1), 8797. http://doi.org/10.21272/fmir.5(1).87-97.2021

Received: 15 February 2021

Accepted: 2 March 2021

Published: 30 March 2021

Copyright: (C) 2021 by the authors. Licensee Sumy State University, Ukraine. This article is an open access article distributed under the terms and conditions of the Creative Commons Attribution (CC BY) license (https://creativecommons.org/licenses/by/4.0/)

\section{Introduction}

Less than one year ago the article «The rise of online banks in Italy "WIDIBA Bank" Case Study» (Faccia et al., 2020) [1] was published, and many researchers already downloaded and cited it, demonstrating the high interest in the topic. The case study is particularly appealing since it is a leading example of how latecomers can succeed in the fintech industry. A further analysis, using the PESTLE approach (Starnawska, 2021) [2], is therefore carried out, aiming at better defining the context in which "Widiba Bank" is operating. Strategies and performances are therefore assessed, using the DEA Analysis methodology (Cooper et al. 2006) [3], testing and comparing the results of all the (fully) online banks in Italy.

Opening an online bank account is valuable for many reasons. Thanks to technological evolution and internet banking it is no longer essential to have access to a physical bank to open an account, manage it or carry out banking transactions. Choosing a mobile or multi-channel bank may be the right option for those who want flexibility and convenience. Unlike branches, online banking ensures access 24 hours a day, 7 days a week from any device connected to the internet (smartphone, smartwatch, tablet, etc.).

According to the Governor of the Bank of Italy Ignazio Visco (2021) [4], the small and medium-sized banks in the euro area will be the ones that will suffer the most from the economic consequences of the pandemic. The Covid19 emergency has accelerated the digitization of the financial and insurance sector, changing the needs and habits of customers and SMEs in their interaction with banks and insurance companies, pushing traditional operators to 
open up to collaborations with a startup ecosystem and non-financial players, while new business opportunities have arisen for the new innovative Fintech and Insurtech companies. During the lockdown, Italian banks' customers, like in any other part of the world, were forced to interact with their bank only online and most of them declared to be satisfied with the service received thanks to digital tools, in particular the ability to easily perform online transfers and payments, interact with the personal and digitally sign documents. In April 2020, the customers' online banks increased by an average of $17 \%$ compared to the same period in 2019, digital transactions grew by $32 \%$ and new digitally acquired customers rose by 75\% (Carmignani et al., 2020) [5]. The use of Fintech and Insurtech services has grown, in particular those of digital identity (used by $48 \%$ of consumers), of telemedicine included in the policy (6\%), and of Robo Advisory (6\%), even if for some the effect could be short-term, linked to contingent needs, according to updated reports (2020) [6]. Italian consumers confirm their trust in traditional institutions: among consumers who would turn to at least one actor for various services, $72 \%$ would entrust savings management and $65 \%$ would ask for a loan to their bank, $83 \%$ would insure health with an insurance company. But they are increasingly aimed at experimenting with less traditional players: for small loans, $53 \%$ would also rely on innovative players, including smartphone manufacturers like Apple and Samsung (21\%), startups (19\%), eCommerce sites like Amazon (19\%) and internet companies such as Google and Facebook (17\%). Over 300 Italian Fintech and Insurtech started up in 2020 [5].

It has been demonstrated (Moşteanu et al., 2020) [7] that the bank of the future, according to the needs of consumers, is characterized by the speed in carrying out operations and greater transparency of investments, flexible opening hours, and availability up to the possibility of carrying out any activity from mobile. Similar wishes characterize the insurance company of the future: consumers want speed from the company in solving problems and settling claims, simplicity, and transparency in signing policies and responding to complaints, but also 24/7 availability and the ability to do everything remotely.

During the second lockdown, the technology (Moşteanu and Faccia, 2021) [8] made it possible to remove barriers and distances, allowing the ongoing of multiple activities. There has been a sharp increase in the use of digital financial services and online channels in general. In the new market scenario that has arisen, the needs and requirements of consumers have changed and so has changed the way they access and use services. Greater openness and greater collaboration of traditional operators were boosted with startups and non-financial actors and it has led to the emergence of new business opportunities for fintech and insurance companies, i.e. operating in the financial and insurance.

Furthermore, the ability to adapt and innovate has enabled fintech and insurtech startups to avoid the negative impact of the COVID-19 emergency, quickly adapting to the new socio-economic context.

Companies seek to offer new services and use new ways of offering to meet customer needs, including:

$>\quad$ quick feedback, because the consumer wants to be able to perform operations quickly and wants companies to be reactive, always guaranteeing safety and transparency;

$>\quad$ ease of interaction, because consumers expect barriers and difficulties for accessing the requested services/products to be eliminated;

$>\quad$ integrated and tailored services, since the possibility of being able to take advantage of multiple services, is appreciated, even more so if customized based on individual needs and requirements.

\section{Literature Review}

Engaging with the bank away from the branch represents the way that most leads to competing on the same ground as FinTechs. Even today in the Western world, the use of home banking is limited in absolute terms and concentrated on certain groups of subjects, with certain age characteristics and cultural level. The era we are living in will exponentially accelerate its spread if the banks want to do so. First of all, it will be necessary to dramatically increase the level and set of technologies available. As the experiences already started in the Far East show (Nguyen et al., 2020) [9], banks will have to rapidly adopt data analytics and artificial intelligence tools. These and other means will improve both the relationship with customers and the ability to design new products and services. Anticipating requests and needs, even thinking about the post-emergency phase, must become a formula for strengthening the bank-customer relationship. The active use of the large amount of data that banks have available today will allow us to better define the customer's profile, the level of risk, and his preferences. Similarly, the use of behavioral economics tools will make it possible to fine-tune the services to be offered with greater detail and effectiveness. A 
mix of micromarketing and behavioral economics, supported by work on big data, to analyze and interpret the needs of customers and get in touch with them, to make proposals tailored to individual needs.

In recent years, across the world, branches have become a cost burden on the banking system, but sometimes they are still considered an important point of reference for individuals and businesses. Indeed, territorial proximity, which is also knowledge of who resides and works in a given context, offers the possibility of intervening more effectively in the assessment of credit and its disbursement. It allows the local community to feel the proximity of the bank. Although the operational effectiveness of the branches must continue to be improved, to alleviate the burden of their costs on the income statement of the banks, it is difficult not to see their revitalization as key points of relationship with the customer today.

The PESTLE analysis is therefore an excellent tool to be used to study the external factors of the context in which a business is operating. It is usually very difficult to graphically represent the interactions of all the endogenous and exogenous factors that might affect the performances. Thus, the first step of the PESTLE analysis is usually the draft of a map of the external systems. The organization should be placed at the center of the map and then, through brainstorming direct and indirect stakeholders are listed. Next, the connections among the parts should be identified. Finally, any significant influence from the external environment or infrastructure should be included in the map as well. The PESTLE analysis (Phan, 2021; Cadle et al. 2010; Sanjeepan, 2017) [10-12] is used to study the market of a particular organization and takes its name from the following: a) Political, b) Economic, c) Social, d) Technological, e) Legal, f) Environmental. Such an analysis serves to identify what is happening in the external environment of an organization and the factors that could influence its future trends and performances.

Precursors of modern online banking services were the first banking services that, starting from the early $80 \mathrm{~s}$, allowed the use of remote banking services through the use of electronic media (Acharya et al., 2008) [13]. The phrase "online banking" became popular in the late 1980s, and mainly indicated the use of a terminal, keyboard, and monitor to access the banking system, transmitting information over a common telephone line (Sikdar and Makkad, 2013) [14]. In some cases, the interaction with the online bank took place through the use of a numeric keypad that encoded the instructions for the bank intones, transmitted over the normal telephone line. The first real online services began to operate in 1981 in New York when four of the main local banks (Citibank, Chase Manhattan, Chemicals, and Manufacturer Hannover) offered online banking services usable through the Videotex system (Boni and Tsekeris, 2007) [15]. This system soon met with failure in much of the world. The United Kingdom was an exception and developed the technology adequately until in 1983 it created the first institution able to offer online banking services from home: the Nottingham Building Society. The infrastructure used was based on the Prestel system (Dover, 1988; Tait and Davis, 1989) [16-17], usable via a computer or keyboard, connected to the telephone network and home television. In this way, the user of the online bank could query his account and consult his updated balance, or even take advantage of operations such as bank transfers or various payments (the most made were related to the bill for the electricity supply, telephone, or of gas). The first financial institution to offer Internet Banking was the Stanford Federal Credit Union, which made the first online bank available to its customers in October 1994 (Sharma, 2014; Walker and Morris, 2021) [18-19].

Many pieces of research are already performed with the application of the Data Envelopment Analysis to the Banking Industry. It can be also stated that this sector is one of the best fields to test the methodology (Abidin et al., 2021; Wu et al. 2006; Rehman, 2015) [20-22]. In this case, the methodology will be applied to focus on the performances of online banks performances in Italy.

\section{Methodology and research methods}

This research is based on a case study analysis, deepening previous research, addressing previously identified limitations. The analyses are performed using well known and recognized tool so-called PESTLE analysis. It is demonstrated as particularly suitable for a comprehensive analysis of the context, addressing strategic perspectives and expectations. The success of the company is later confirmed through a performance analysis carried out using the DEA Methodology, which is considered one of the best for comparative studies. The dataset is small but complete, as it includes all the companies that are currently operating in the same industry as Widiba, the (fully) online banks in Italy, namely a) Wise Dialog Bank S.p.A.(WIDIBA), b) IW Bank S.p.A., c) Chebanca! S.p.A., d) Finecobank S.p.A.. ING Bank N.V. (Netherland) and N26 Bank Gmbh, although Widiba direct competitors, were excluded as they are not based in Italy and therefore not comparable. The 
financials of each bank are retrieved from the official financial statements directly downloaded by the Italian Registry of Incorporated Companies on 08.03.2021.

Two main research questions are addressed by this article: a) is it possible to identify, through a PESTLE analysis, the most important strategic factors that are currently influencing the performances of Widiba? b) is it possible to verify if Widiba, as a latecomer in the industry, demonstrated to be competitive in the challenging market of the (fully/mainly) online banks in Italy?

Results. PESTLE Analysis In this section the results of the PESTLE Analysis are presented first to identify the most important exogenous strategic factors that affect the industry of online banks in Italy. Then the results of the DEA Analysis are provided to support the hypothesis that Widiba successfully survived and emerged in this challenging environment, although joining the competition later than all the other competitors. The matching between PESTLE strategic factors and the successful performance of a latecomer will investigate the key actions adopted by Widiba, considered as a leading example to thrive in the challenging digital markets.

a) Political

The Italian political situation has changed due to the consequences generated by the Covid 19 pandemic. In more detail, the political framework has been affected:

$>$ by the measures implemented by the government to prevent the outbreak of epidemics and to overcome the crisis of the National Health System (overcrowding of intensive care units and impossibility of guaranteeing other health services), which have brought to light the fragility of our administrative system;

$>$ the social distancing measures implemented to limit the spread of the coronavirus among citizens, the so-called "lockdown" which has had a strong negative impact on the economy (Piccinini et al., 2020) [23];

$>$ by the measures implemented by the European Union to help the most economically fragile countries to overcome the impact of the economic crisis generated by the aforementioned measures to face the pandemic.

The consequences on the Italian political framework are manifold but it is still too early to make final assumptions as the pandemic is still ongoing. The peak of the health crisis seems to have been passed, the depressive action of the lockdown on the economic system has ended but the extent of the economic damage to the production system is enormous. The Italian government and the European Union have implemented both emergency and medium-term measures, partially already implemented and partially yet to be activated, whose effectiveness is still to be verified. An uncertain and difficult situation towards a solution but which could suddenly precipitate if new outbreaks of Covid-19 out of control should reappear.

The chain of command of the Italian Public Administration has shown all its limits due to a series of political choices of the past which in the name of autonomy have generated a multiplication of local power centers and a sort of institutional anarchy, aggravated by slavish respect bureaucratic rules in order not to incur legal liability. In short, the Public Administration seems to have specialized in the application of unexceptionable formal acts but practically absent choices of merit. In other words, the intervention of a government decree is required to regulate any intervention that may involve objective responsibilities. In this challenging context online banks (Widiba included) managed not only to survive but also to increase their growth rates.

\section{b) Economic}

At the beginning of 1999, with the start of the third phase of economic and monetary union in the European Union, the management of monetary policy (the right to issue money and control of interest rates) was exclusively attributed to the European Central Bank. The Bank of Italy, together with the national banks of eleven other countries, thus renounced its primary functions, while maintaining the supervision and control of the national credit system. Starting in 2006, in response to the growing merger and acquisition processes that witnessed the main European financial institutions as main players, Italian banks also started the process of concentration or the centralization of a significant share of credit activities in a few large banking groups. This path, still active today, led to the formation of about five hundred contemporary Italian credit institutions: among the most important are the Intesa San Paolo Group (2006), Unicredit (2007), Ubi (2007), Banco BPM Group (2017). It is not surprising to notice that all the Italian Online Banks are currently part of the major banking groups. 
The 2015 reform (Law no.33 / 2015) was also aimed at adapting those financial institutions that remained on the margins of the concentration process: co-operative banks, banking foundations, and credit banks.

Despite its relatively young constitution, the Italian banking system has become the protagonist of great changes and transformations, resisting wars, crises, and difficulties. Overall, it has proven to be solid and resilient and has experienced smaller losses and failures than other Western banking systems.

Customers are now used to the universal bank model, aimed at all types of customers and providing multiple investment services: this model has become essential for maintaining an adequate level of international competitiveness. Increasingly complex, dynamic, and connected markets would seem to herald the inevitable continuation of the concentration process in the credit landscape. However, attention should be paid to the systemic dangers to which a market made up of a few large groups exposed to risks.

\section{c) Social}

The main factor in slowing down the technological transformation is internal resistance. In some cases, innovation involves risks, since it pushes us to explore unknown areas. It is not always easy to push a structured and consolidated organization to open up to new processes, also due to the division of internal responsibility. For this, it would be necessary to provide effective governance systems, which push those responsible to face risk as a necessary (and sometimes positive) component of innovation, to incentivize them to propose and accept any critical issues as opportunities to develop original solutions. Besides, the bank may lack the necessary workforce to implement this transformation. Not only banks, but all business sectors need specific skills to cope with digitization. This often results in the creation of new jobs that did not exist before. However, these skills are not always immediately available within the labor market or are not, at least, at convenient conditions. In the case of Widiba, the wide network of consultants that assist the customer already resulted to be a key factor for its success (Faccia et al., 2020) [1].

\section{d) Technological}

Omnichannel, elimination of physical touchpoints and apps for home banking, financial institutions are at a crossroads: innovate or disappear. In any sector, digital transformation and technological innovation represent two challenges, but above all two opportunities not to be missed to remain competitive on the market. This is particularly true for the banking sector, for which the digitization of services is an obligatory step. Moreover, even in other areas, it is the same thing, think of shopping with the advent of e-commerce, or marketing and even communication. Innovate first is the commandment. However, doing so is not always easy.

e) Legal

The banking sector is characterized by stringent regulations. Given its delicate role within each company, the banking sector has complex and articulated legislation, which binds many of the activities that the bank can carry out. Just think, for example, of both brand and product advertising communication, which must be subject to specific requirements, in such a way as to allow the customer to fully understand the products offered and compare the various offers on the market. Transparency and consumer protection are two goals that are always pursued when the regulatory framework for the management and control of retail banking products is outlined. This should not come as a surprise since the business that a bank can carry out is composite. The very services it provides are often sophisticated and complex. All this requires a specific and articulated system of rules. The management possibilities are limited, since the approval and implementation processes take time, while innovation, especially if digital, has a short timeframe.

Financial markets can be divided into three essential branches: banking, asset management, and insurance market. These markets are supervised by specific authorities, aimed at ensuring the public trust of investors, nonprofessional counterparties, and the competitiveness, stability, and proper functioning of the entire financial system. These supervisory authorities, in Italy, are Banca d'Italia (central bank), Consob (the Italian Security Exchange Commission), IVASS (authority for Insurance Companies), and, at the EU level, the European Central Bank (ECB). The regulatory sources are ranked according to a specific hierarchy, summarised as follows: a) Treaties, regulations and directives of the European Community; b) Constitution and constitutional laws; c) Ordinary laws, law decrees and legislative decrees; d) Regional laws; e) Regulations (secondary legislation); f) Normative and contractual habits and uses.

\section{f) Environmental}


All banks now have a Sustainability and Corporate Social Responsibility Department. All financial institutions make massive use of the web and social media for related communication activities, for example by publishing the social report and relevant information on the bank's website; however, not all of them make use of media 2.0 in a meaningful way for sustainability communication. Social media are an important opportunity to communicate the Corporate Social Responsibility of credit companies, due to some concomitant factors: large audiences aggregate on large networks (Facebook and Twitter in particular), with common interests; online activism is increasingly widespread, with voluntary, opinion and social action groups; the "degrees of separation" between different environments and communities are reduced, making it easier for companies to identify, reach and involve these groups. This allows to move from a traditional philanthropic approach - the bank as a sponsor of initiatives carried out by non-profit entities - to a more direct and therefore more visible commitment; for example, by transferring to non-profit organizations no longer or not only economic resources, but also non-economic resources such as their know-how; o involving its employees in commitment actions on social issues. In Italy, as in many other countries, banks are starting to consider and work intensively on CSR. In many cases they limit themselves to republishing the contents of the sustainability report on institutional social profiles (for example the bank's Social media pages); The comparison with non-profit organizations is interesting, in which on average there is a much greater commitment on social media, to gain visibility, raise awareness, and increasingly also to raise funds.

\section{Results}

DEA Analysis. One of the main challenges that every organization must face to assume or maintain a leadership role in its core business consists of knowing how to measure and evaluate company performance concerning its strategic objectives. they are called upon to change and innovate at a strategic, operational, and management level. The innovation process is a critical success factor to be applied to business processes, which must be configured as effective and efficient to support organizational strategies. Of fundamental importance is therefore the alignment of business processes with corporate strategies aimed at guaranteeing the company a lasting competitive advantage. Over the years, numerous models for performance evaluation have been developed to give management an overall view of the company's work and guide it in the implementation of processes that are continuously more integrated and aligned with corporate purposes. The DEA methodology is commonly recognized as a valid tool for analyzing the production efficiency of company business units.

All Italian banks that operate exclusively online, except Widiba, were established in the 1990s. Widiba, after a relatively long incubation period, was founded in 2014. However, this late entry into the market did not prevent the Widiba bank from competing. with those already existing. After the first 4 years of operation in which there were losses, in 2018 it finally registered profits. Therefore, comparing the performances of the 4 Italian banks that operate exclusively online, the following parameters were included in the analyzes: a) ROE (Input), b) Deposits growth rate (Input), c) Assets Growth Rate. Although the ROE is not particularly brilliant for Widiba, the growth is impressive, which is more than double that of other competitors. Using the official DEA Solver software, and executing the function CCR-Output oriented, the outcomes seem surprising as three banks resulted in the most efficient, among them Widiba (see Figures 1-3). The only company that resulted as underperforming is "Chebanca! S.p.A." in the assessed period 2016/2019 (see Tables 1-7).

Figure 1, clearly shows the three banks that maximized their performances and the underperformer "CheBanca! S.p.A."

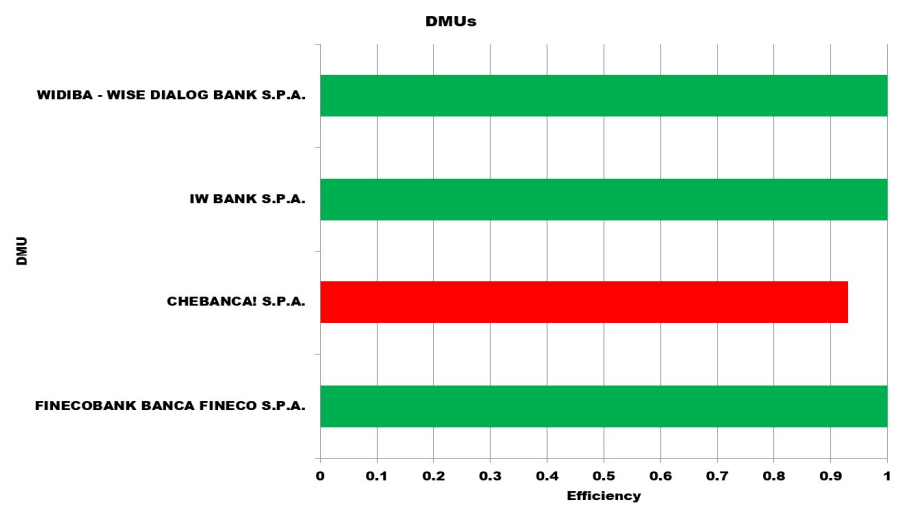

Figure 1. DEA Ranking

Source: developed by the authors (Starting from the use of the DEA SOLVER software) 
Figure 2, includes the full outcome provided by the DEA Solver software, along with the input details.

\begin{tabular}{|c|c|c|c|}
\hline \multicolumn{3}{|c|}{ DEA model = DEA-Solver LV8.0/ CCR(CCR-O) } & \\
\hline \multicolumn{4}{|l|}{ Problem $=$ DMUs } \\
\hline \multicolumn{4}{|l|}{ No. of DMUs $=4$} \\
\hline \multicolumn{4}{|c|}{ Returns to Scale $=$ Constant $(0=<$ Sum of Lambda $<$ Infinity $)$} \\
\hline \multicolumn{4}{|c|}{ No. of Input items $=2$} \\
\hline \multicolumn{4}{|l|}{ Input(1)= ROE } \\
\hline \multicolumn{4}{|c|}{ Input $(2)=$ DEPOSITSGROWTH } \\
\hline \multicolumn{4}{|l|}{ No. of Output items $=1$} \\
\hline \multicolumn{4}{|c|}{ Output(1) = ASSETSGROWTH } \\
\hline \multicolumn{4}{|c|}{ Statistics on Input/Output Data } \\
\hline & ROE & DEPOSITSGROWTH & ASSETSGROWTH \\
\hline Max & 0.43617991 & 0.29513207 & 0.275367987 \\
\hline Min & -0.026472268 & 0.069110297 & 0.06888327 \\
\hline Average & 0.121565131 & 0.15344493 & 0.146954212 \\
\hline SD & 0.183837043 & 0.087307632 & 0.07858145 \\
\hline \multicolumn{4}{|l|}{ Correlation } \\
\hline & ROE & DEPOSITSGROWTH & ASSETSGROWTH \\
\hline ROE & 1 & -0.480187664 & -0.440725131 \\
\hline DEPOSITSGROWTH & -0.480187664 & 1 & 0.998723436 \\
\hline ASSETSGROWTH & -0.440725131 & 0.998723436 & 1 \\
\hline \multicolumn{4}{|l|}{ No. of Efficient DMUs $=3$} \\
\hline \multicolumn{4}{|l|}{ No. of Inefficient DMUs = 1} \\
\hline \multicolumn{4}{|c|}{ [CCR-O] LP started at 03-08-2021 20:16:31 } \\
\hline \multirow{2}{*}{\multicolumn{3}{|c|}{\begin{tabular}{|l|} 
Finished at $03-08-2021 \quad 20: 16: 32$ \\
Elapsed time $=1$ seconds
\end{tabular}}} & \\
\hline & & & \\
\hline
\end{tabular}

Figure 2. DEA Results

Source: developed by the authors (Starting from the use of the DEA SOLVER software)

Figure 3, shows in detail scores and the rankings outcomes.

Model = CCR-O
\begin{tabular}{|c|c|c|c|}
\hline No. & DMU & Score & Rank \\
\hline 1 & FINECOBANK BANCA FINECO S.P.A. & 1 & 4 \\
\hline 2 & CHEBANCA! S.P.A. & 0.9307 & 1 \\
\hline 3 & IW BANK S.P.A. & 1 & 1 \\
\hline 4 & WIDIBA - WISE DIALOG BANK S.P.A. & 1 & \\
\cline { 2 - 3 } & Average & 0.9827 & \\
\cline { 2 - 3 } & Max & 1 & \\
\cline { 2 - 3 } & Min & 0.9307 & \\
\cline { 2 - 3 } & St Dev & 0.0347 & \\
\end{tabular}

Figure 3. DEA Results

Source: developed by the authors (Starting from the use of the DEA SOLVER software)

Table 1, discloses the values of Equity capital of the companies analyzed, including the average, which are considered the inputs of the DEA Analysis.

Table 1. Italian Online Banks - Equity Capital

\begin{tabular}{|c|c|c|c|c|}
\hline Banks & $\mathbf{2 0 1 9}$ & $\mathbf{2 0 1 8}$ & $\mathbf{2 0 1 7}$ & $\mathbf{2 0 1 6}$ \\
\hline FINECOBANK BANCA FINECO S.P.A. & $587,334,184$ & $558,380,149$ & $517,706,000$ & $469,455,000$ \\
\hline CHEBANCA! S.P.A. & $328,637,852$ & $341,830,877$ & $328,710,389$ & $223,535,241$ \\
\hline IW BANK S.P.A. & $141,659,367$ & $137,317,285$ & $144,608,000$ & $150,984,909$ \\
\hline WIDIBA - WISE DIALOG BANK S.P.A. & $125,367,279$ & $123,816,637$ & $139,018,494$ & $81,225,770$ \\
\hline
\end{tabular}

Sources: Companies' Official Financial Statements retrieved from the Italian Registry of Incorporated Companies on 08.03.2021.

Table 2, discloses the values of Net results (for each period) of the companies analyzed, including the average, which are considered the inputs of the DEA Analysis.

Table 2. Italian Online Banks - Net Results

\begin{tabular}{|c|c|c|c|c|}
\hline Banks & $\mathbf{2 0 1 9}$ & $\mathbf{2 0 1 8}$ & $\mathbf{2 0 1 7}$ & $\mathbf{2 0 1 6}$ \\
\hline FINECOBANK BANCA FINECO S.P.A. & $285,891,403$ & $227,922,326$ & $214,120,000$ & $211,844,000$ \\
\hline CHEBANCA! S.P.A. & $17,230,121$ & $18,999,229$ & $16,407,187$ & $4,251,241$ \\
\hline IW BANK S.P.A. & $10,886,090$ & $4,457,688$ & $-5,433,571$ & $-6,913,282$ \\
\hline WIDIBA - WISE DIALOG BANK S.P.A. & $1,896,669$ & $1,550,642$ & $-14,884,627$ & $-12,210,445$ \\
\hline
\end{tabular}

Sources: Companies' Official Financial Statements retrieved from the Italian Registry of Incorporated Companies on 08.03.2021. 
Table 3, discloses the values of Deposits (received both from other banks and customers) of the companies analyzed, including the average, which are considered the inputs of the DEA Analysis.

Table 3. Italian Online Banks - Deposits (from banks and customers)

\begin{tabular}{|c|c|c|c|c|}
\hline Banks & $\mathbf{2 0 1 9}$ & $\mathbf{2 0 1 8}$ & $\mathbf{2 0 1 7}$ & $\mathbf{2 0 1 6}$ \\
\hline FINECOBANK BANCA FINECO S.P.A. & $26,189,531,446$ & $23,248,430,877$ & $21,131,037,000$ & $19,912,179,000$ \\
\hline CHEBANCA! S.P.A. & $21,105,140,441$ & $19,503,383,597$ & $18,553,228,339$ & $13,977,642,357$ \\
\hline IW BANK S.P.A. & $3,683,509,190$ & $3,110,536,475$ & $3,073,587,059$ & $3,039,828,325$ \\
\hline WIDIBA - WISE DIALOG BANK S.P.A. & $3,564,076,242$ & $3,077,622,087$ & $2,211,432,064$ & $1,655,700,817$ \\
\hline
\end{tabular}

Sources: Companies' Official Financial Statements retrieved from the Italian Registry of Incorporated Companies on 08.03.2021.

Table 4, discloses the values of Total Assets of the companies analyzed, including the average, which are considered the inputs of the DEA Analysis.

Table 4. Italian Online Banks - Total Assets

\begin{tabular}{|c|c|c|c|c|}
\hline Banks & $\mathbf{2 0 1 9}$ & $\mathbf{2 0 1 8}$ & $\mathbf{2 0 1 7}$ & $\mathbf{2 0 1 6}$ \\
\hline FINECOBANK BANCA FINECO S.P.A. & $27,996,387,083$ & $24,713,574,509$ & $22,340,335,000$ & $20,986,376,000$ \\
\hline CHEBANCA! S.P.A. & $21,542,777,345$ & $20,158,381,720$ & $19,309,212,616$ & $14,689,824,018$ \\
\hline IW BANK S.P.A. & $3,849,775,792$ & $3,256,978,902$ & $3,211,915,832$ & $3,178,190,036$ \\
\hline WIDIBA - WISE DIALOG BANK S.P.A. & $3,792,229,940$ & $3,304,224,165$ & $2,458,299,898$ & $1,842,385,035$ \\
\hline
\end{tabular}

Sources: Companies' Official Financial Statements retrieved from the Italian Registry of Incorporated Companies on 08.03.2021.

Table 5, discloses the values of ROE (Return of Equity) of the companies analyzed, including the average, which are considered the inputs of the DEA Analysis. ROE is calculated as a ratio between Net-Results and Total Equity.

Table 5. Italian Online Banks - ROE

\begin{tabular}{|c|c|c|c|}
\hline Banks & $\mathbf{2 0 1 9}$ & $\mathbf{2 0 1 8}$ & $\mathbf{2 0 1 7}$ \\
\hline FINECOBANK BANCA FINECO S.P.A. & $48.68 \%$ & $40.82 \%$ & $41.36 \%$ \\
\hline CHEBANCA! S.P.A. & $5.24 \%$ & $5.56 \%$ & $4.99 \%$ \\
\hline IW BANK S.P.A. & $7.68 \%$ & $3.25 \%$ & $-3.76 \%$ \\
\hline WIDIBA - WISE DIALOG BANK S.P.A. & $1.51 \%$ & $\mathbf{4 3 . 6 2 \%}$ & $\mathbf{5 . 2 6 \%} \%$ \\
\hline
\end{tabular}

Sources: Own calculation (Net results / Equity).

Table 6, discloses the values of ROE Deposits Annual Growth of the companies analyzed, including the average, which are considered the inputs of the DEA Analysis. It is calculated as [(Deposit of the period/Deposits of the previous period) -1$]$.

Table 6. Italian Online Banks - Deposits Annual Growth

\begin{tabular}{|c|c|c|c|}
\hline Banks & $\mathbf{2 0 1 9}$ & $\mathbf{2 0 1 8}$ & $\mathbf{2 0 1 7}$ \\
\hline FINECOBANK BANCA FINECO S.P.A. & $12.65 \%$ & $10.02 \%$ & $6.12 \%$ \\
\hline CHEBANCA! S.P.A. & $8.21 \%$ & $5.12 \%$ & $32.74 \%$ \\
\hline IW BANK S.P.A. & $18.42 \%$ & $1.20 \%$ & $\mathbf{9 . 6 0 \%} \%$ \\
\hline WIDIBA - WISE DIALOG BANK S.P.A. & $15.81 \%$ & $39.17 \%$ & $\mathbf{1 5 . 3 6 \%}$ \\
\hline
\end{tabular}

Sources: Authors' calculation [(Deposits current year / Deposit previous year) - 1].

Table 7, discloses the values of ROE Assets Annual Growth of the companies analyzed, including the average, which are considered the inputs of the DEA Analysis. It is calculated as [(Assets of the period/Assets of the previous period) -1$]$.

Table 7. Italian Online Banks - Assets Annual Growth

\begin{tabular}{|c|c|c|c|}
\hline Banks & $\mathbf{2 0 1 9}$ & $\mathbf{2 0 1 8}$ & $\mathbf{2 0 1 7}$ \\
\hline AINECOBANK BANCA FINECO S.P.A. & $13.28 \%$ & $10.62 \%$ & $6.45 \%$ \\
\hline CHEBANCA! S.P.A. & $6.87 \%$ & $4.40 \%$ & $31.45 \%$ \\
\hline IW BANK S.P.A. & $18.20 \%$ & $1.40 \%$ & $1.06 \%$ \\
\hline WIDIBA - WISE DIALOG BANK S.P.A. & $14.77 \%$ & $34.41 \%$ & $\mathbf{1 0 . 1 2 \%}$ \\
\hline
\end{tabular}

Sources: Authors' calculation [(Assets current year / Assets previous year) - 1].

\section{Discussion}

The main trend of technological innovation is to rethink retail structures. The bank has always been one of the service providers that are intangible, inseparable (since there is no temporal separation between production 
and use), heterogeneous (since they vary from customer to customer), and perishable (since they cannot be stored, stored and used at a later time).

Precisely in light of the product characteristics, a key element of the marketing strategies for all financial institutions was a physical presence. It was, in fact, essential to safeguard the territory both in terms of communication (eg poster design, leafleting, etc.) and in the development of functional touchpoints to develop the relationship with customers. This is demonstrated by the fact that in 2012 there were 32,881 branches in Italy and that the number of branches of some of the main Italian banks exceeded (and by no means a little) the number of points of sale of the most important large-scale retailers. On the contrary, 2019, even more so than 2018, will be dedicated to "Phygital" delivery. Not only will there be a constant closure of branches and a reduction in the branches operating throughout the country (it will reach 24,000 offices), but the distribution of services will be reorganized, so that they can be used on the internet, from the computer or the telephone. In this way, it will be possible to achieve significant savings in terms of costs related to the maintenance of physical points and will better meet the needs of customers.

By omnichannel vision, we mean that organizational approach aimed at integrating the physical and digital channels in such a way as to offer the customer a unique and in some ways unrepeatable shopping experience (in a broad sense). In other words, all banks or companies are starting to use all the communication channels they have available to reach the customer (or potential customer) and carry out retail activities, but also branding or awareness. In this way, it is possible to integrate, for example, telephone communication (SMS), with digital communication (e-mail), and with offline communication (the branch or the counter), thus creating an ecosystem of perfectly integrated and coordinated channels that can be activated. in a different way based on the type of customer, you want to reach. Ultimately, the goal is always the same: to offer a unique and personalized customer experience to effectively convey your messages. The banks, in essence, have realized that each customer is looking for a personalized experience, which meets his needs and his needs as closely as possible. This type of experience necessarily passes from digital to mobile.

In terms of marketing, banks are starting to adopt a strategic approach, i.e. they aim to develop a systemic vision of the market, taking into account the characteristics of the reference market and the needs of target customers. Indeed, it is no longer sufficient to pursue a purely operational marketing model, in the short or medium term, in which objectives to be achieved are established, in terms of market share and positioning, using a marketing mix consisting of product, price. , promotion, and point of sale. On the contrary, to have good results, especially in communication, it is necessary to develop a broader strategy, which aims to consolidate the relationship with the customer, who, especially with the advent of social media, has become more demanding. For this reason, sector communication is radically changing. In this sense, it is essential to focus on a few clear and essential messages. At the same time, it is also necessary to simplify all types of processes. For example, it was observed that the quality of the customer experience perceived by users/customers varies considerably based on time: the less time it takes to complete an action, the higher the service will be considered.

Hybridization of the relationship with customers through the search for the right balance between personal and digital relationships, massive use of innovative tools made available by ICT technologies, are the two key aspects around which to redesign the role of banks in the economic and social context that is taking shape.

\section{Conclusions}

The Widiba case is extremely interesting because it can identify, in the particular Italian context, how a correct analysis of the factors, accompanied by adequate solutions, allows new entrants to emerge and compete by breaking down every barrier to entry. The performances of Widiba Bank, in particular in terms of growth, are outstanding, and double the other competitors in the four years analyzed. The combination of the PESTLE analysis with the empirical verification of performance using the DEA methodology allowed the authors to identify the determining factors for the success of a very competitive business, centered in a technological context.

Author Contributions: conceptualization, A.F. and L.P.L.C.; methodology, A.F.; software, A.F.; validation, A.F.; formal analysis, A.F., and L.P.L.C.; investigation, A.F., and L.P.L.C.; resources, A.F. and L.P.L.C.; data curation, A.F.; writing-original draft preparation, A.F., and L.P.L.C.; writing-review and editing, A.F.; visualization, A.F.; supervision, A.F.; project administration, A.F.

Funding: This research received no external funding. 


\section{References}

1. Faccia, A., Moşteanu, N. R., Cavaliere, L. P. L., \& Santis, G. (2020). The rise of online banks in Italy "WIDIBA Bank" Case Study. Financial Markets, Institutions, and Risk, 4(2). https://doi.org/10.21272/fmir.4(2).80-97.2020.

2. Starnawska, S. E. (2021). Sustainability in the Banking Industry Through Technological Transformation. In The Palgrave Handbook of Corporate Sustainability in the Digital Era (pp. 429-453). Palgrave Macmillan, Cham. https://doi.org/10.1007/978-3-030-42412-1_22

3. Cooper, W. W., Seiford, L. M., \& Tone, K. (2006). Introduction to data envelopment analysis and its uses: with DEA-solver software and references. Springer Science \& Business Media. Retrieved from: https://www.springer.com/gp/book/9780387452814

4. Visco, I., Keynote speech by the SRB Chair at the Banca d'Italia workshop on the crisis management framework for banks in the EU on 15th January 2021 (virtual event) "The crisis management framework for banks in the EU: what can be done with small and medium-sized banks?" Retrieved from: https://srb.europa.eu/en/node/1118

5. Carmignani, A., Manile, M., Orame, A., \& Pagnini, M. (2020). Servizi bancari online e dinamica degli sportelli bancari (Online Banking Services and Branch Networks). Bank of Italy Occasional Paper, (543). Retrieved from: https://www.osservatori.net/it/ricerche/comunicati-stampa/fintech-digital-finance-quale$\underline{\text { modello-per-litalia }}$

6. Moşteanu, D., Roxana, N., Faccia, D., Cavaliere, L. P. L., \& Bhatia, S. (2020). Digital technologies' implementation within financial and banking system during socio distancing restrictions-back to the future. International Journal of Advanced Research in Engineering and Technology, 11(6). Retrieved from: https://papers.ssrn.com/sol3/papers.cfm?abstract id $=3650810$

7. Mosteanu, N. R., \& Faccia, A. (2021). Fintech Frontiers in Quantum Computing, Fractals, and Blockchain Distributed Ledger: Paradigm Shifts and Open Innovation. Journal of Open Innovation: Technology, Market, and Complexity, 7(1), 19. https://doi.org/10.3390/joitmc7010019

8. Nguyen, D. T. T., Diaz-Rainey, I., \& Roberts, H. (2020). The Impact of Banking Integration on East Asian Commercial Banks. Macroeconomic Stabilization in the Digital Age, 141

9. Phan, S. (2021). The effect of PESTLE factors on development of e-commerce. International Journal of Data and Network Science, 5(1), 37-42. Retrieved from: http://www.growingscience.com/ijds/ Vol5/ijdns_2020_28.pdf

10. Cadle, J., Paul, D., \& Turner, P. (2010). Business analysis techniques. British Informatics Society Limited.Retrieved from: https://www.academia.edu/11176141/Business Analysis Techniques 72 Essential Tools for Success

11. Sanjeepan, N. (2017). Strategic Analysis and Strategic Planning for Commercial Banking (An Analysis based a Commercial Bank operating in Sri Lanka). Retrieved from: https://www.semanticscholar.org/paper/Strategic-Analysis-and-Strategic-Planning-for-(An-a-Sanjeepan/2de 4c86112adf0faf107932d52a19ccb5bd1f7ca

12. Acharya, R. N., Kagan, A., \& Lingam, S. R. (2008). Online banking applications and community bank performance. International Journal of Bank Marketing. https://doi.org/10.1108/02652320810902442

13. Sikdar, P., \& Makkad, M. (2015). Online banking adoption. International Journal of Bank Marketing. Retrieved from: https://www.emeraldgrouppublishing.com/journal/ijbm

14. Boni, K., \& Tsekeris, C. (2007). Electronic Banking. The Blackwell Encyclopedia of Sociology. https://doi.org/10.1002/9781405165518.wbeose103

15. Dover, P. A. (1988). The Effect of Technology Selection on Consumer Adoption of In-home Computerised Banking. International Journal of Bank Marketing. https://doi.org/10.1108/eb010829

16. Tait, F., \& Davis, R. H. (1989). The development and future of home banking. International Journal of Bank Marketing, 7(2), 3-9. https://doi.org/10.1108/EUM0000000001452 
17. Sharma, S. (2014). The Pragmatic Review On Internet Banking And Associated Services In India. International Journal of Computing and Corporate Research,4(4). Retrieved from: https://www.ijccr.com/July2014/20.pdf

18. Walker, T., \& Morris, L. (2021). The Handbook of Banking Technology. John Wiley \& Sons. Retrieved from: https://www.fintechfutures.com/library/the-handbook-of-banking-technology/

19. Abidin, Z., Prabantarikso, R. M., Wardhani, R. A., \& Endri, E. (2021). Analysis of Bank Efficiency Between Conventional Banks and Regional Development Banks in Indonesia. The Journal of Asian Finance, Economics, and Business, 8(1), 741-750. https://doi.org/10.13106/jafeb.2021.vol8.no1.741

20. Wu, D. D., Yang, Z., \& Liang, L. (2006). Efficiency analysis of cross-region bank branches using fuzzy data envelopment analysis. Applied Mathematics and Computation, 181(1), 271-281. Retrieved from: https://www.infona.pl/resource/bwmeta1.element.elsevier-702e0ed9-5eaf-3258-81ac-2ceaa80a37a2

21. Rehman, R. U., Zhang, J., Ali, R., \& Qadeer, A. (2015). Does growing economy and better governance impede banking efficiency? A DEA analysis. Journal of Applied Business Research (JABR), 31(6), 22132224. https://doi.org/10.19030/jabr.v31i6.9478

22. Piccinini, D., Giunchi, C., Olivieri, M., Frattini, F., Di Giovanni, M., Prodi, G., \& Chiarabba, C. (2020). COVID-19 lockdown and its latency in Northern Italy: seismic evidence and socio-economic interpretation. Scientific reports, 10(1), 1-10. Retrieved from: https://www.nature.com/articles/s41598-020$\underline{73102-3}$ 